\title{
TRANSUMBILICAL (OPEN) REPAIR OF UMBILICAL AND PARAUMBILICAL HERNIA
}

\author{
Ramraj R', Vishnu M. L $L^{2}$
}

${ }_{1}^{1}$ Senior Consultant Surgeon, Department of General Surgery, SUT Hospital, Pattom, Thiruvananthapuram.

2Assistant in the Department, Department of General Surgery, SUT Hospital, Pattom, Thiruvananthapuram.

\section{ABSTRACT}

\section{BACKGROUND}

The conventional open repair of umbilical and paraumbilical hernias have been mostly replaced by laparoscopic repair ${ }^{1}$ and this has become almost the rule of the day. The conventional open repairs of umbilical and paraumbilical hernias namely Mayo's repair or other types of repair ${ }^{2}$ with or without mesh are still in vogue in different centres. These are carried out through a subumbilical or circumumbilical incision. A novel idea of access through the umbilicus is made in this study.

The purpose of this study is to assess the functional and cosmetic outcome of transumbilical repair of umbilical and paraumbilical hernias.

\section{MATERIALS AND METHODS}

The study was an observational one carried out successfully on 64 patients in the Department of General Surgery, SUT Hospital, Pattom, Thiruvananthapuram from April 2014 to October 2015. In all the patients, a transumbilical repair was carried out by a single surgeon (myself). The functional and cosmetic outcome was assessed by absence of complications and recurrence of hernia and the cosmetic outcome measured by visual analogue score at 6 months, 12 months and 18 months.

\section{RESULTS}

Among the 64 patients who underwent the transumbilical repair, 12 were males and 52 were females. No patient had recurrence of hernia on follow-up at 6,12 and 18 months. The visual analogue score after repair assessed by the patient was a score of 1 and that of a blinded peer was 0 - 1 with practically no discrepancy from the normally looking umbilicus.

\section{CONCLUSION}

The transumbilical repair gives an opportunity not only for the surgical correction of the hernia with or without a mesh, but also it gives room for reconstructing the umbilicus. There is no significant scar in the vicinity of the umbilicus, thus making this technique superior to the conventional surgery or even laparoscopic surgery.

\section{KEYWORDS}

Transumbilical Repair, Umbilical Hernia, Paraumbilical Hernia.

HOW TO CITE THIS ARTICLE: Ramraj R, Vishnu M L . Transumbilical (open) repair of umbilical and paraumbilical hernia. J. Evolution Med. Dent. Sci. 2018;7(06):724-728, DOI: 10.14260/jemds/2018/164

\section{BACKGROUND}

Umbilical and paraumbilical hernia accounts for $10 \%-12 \%^{3}$ of abdominal wall hernias and this forms an important work of general surgeon. Multiparity and obesity are the most important pre-disposing causes. It was Celeus in the first century who first reported repair of umbilical hernia. William Mayo $^{3}$ in 1901 proposed his classical repair using overlap of the periumbilical flaps. The recurrence rate following suture repair was to the tune of $10 \%-30 \%,{ }^{4}$ which was of alarming concern to the surgeons then. With the advent of prosthetic mesh used for repair, the recurrence rate came down to a low $2 \%$. The incision used for the repair was a smiling incision or a midline incision, thinking that any other incision would cause a compromise to the vascularity of umbilical stalk. With the laparoscopic repair coming into vogue, the umbilicus was attended through tiny incisions far away from umbilicus. In both the above scenarios, the cosmetic restructuring of umbilicus was not a possibility.

'Financial or Other Competing Interest': None.

Submission 15-01-2018, Peer Review 27-01-2018,

Acceptance 29-01-2018, Published 05-02-2018.

Corresponding Author:

Dr. Ramraj $R$,

Senior Consultant Surgeon,

SUT Hospital, Pattom, Thiruvananthapuram.

E-mail: ramrajr69@gmail.com

DOI: $10.14260 /$ jemds $/ 2018 / 164$
Following the old conventional repair or laparoscopic repair the patient was left with no option but to accept a deformed, unsightly, shrivelled umbilicus. In a transumbilical repair the surgeon is blessed with the opportunity of restructuring the redundant skin and thus obtaining a sound vascular, cosmetically acceptable normal looking umbilicus. This study is indented to assess the functional and cosmetic outcome of transumbilical repair of umbilical and paraumbilical hernias.

\section{MATERIALS AND METHODS}

This observational study was conducted on 64 patients admitted in the Department of General Surgery for definitive treatment of umbilical/ paraumbilical hernias. The period of study was from April 2014 to October 2015. The patients were subjected to thorough physical examination and salient points in history were recorded. Emphasis was given to the predisposing causes of hernia and patient was appropriately pre-optimised. Basic investigations were carried out and references to the other concerned departments were made when necessary. All patients underwent routine blood examinations consisting of haemoglobin estimation, total count, differential leucocyte count, ESR, blood sugar, blood urea, serum creatinine, serum sodium and serum potassium. X-ray chest and ECG (all leads) were included in the list of investigations. Ultrasound scan of abdomen was carried out 
to look for any intra-abdominal pathology and also to look for divarication of recti, especially in females.

Those patients who had significant divarication of the recti with umbilical/ paraumbilical hernia were considered for divarication correction with correction of the hernia with abdominoplasty when patient consented for the same. Only those patients who had umbilical/ paraumbilical hernia with no significant divarication are considered in this study.

\section{Operative Technique}

After adequate pre-optimisation and obtaining consent for the transumbilical repair of umbilical/ paraumbilical hernia, the patients were placed on table in the supine position for surgery under General anaesthesia/ spinal anaesthesia/ epidural anaesthesia depending on patient's pre-operative status. Abdominal wall was painted with $10 \%$ povidoneiodine and the area was draped. The first step in the procedure is a hitching stitch in the depth of umbilical scar to evert it to help make the incision along the natural folds of the umbilical pit never extending above the umbilical pit on to the skin surface. Care has to be taken in this step when placing the suture as well as making the incision to avoid inadvertent injury to a possible intestinal loop in the fundus of the sac. Dissection proceeds down till the sac is identified and subsequent dissection in the peri-hernial loose areolar tissue plane to reach the neck of the sac. The linea alba and rectus sheath are defined at least $2 \mathrm{cms}$ all around. A 6'o clock and 12 'o cock incision of the linea alba at least for $1 \mathrm{~cm}$ will help to dilate the neck of the sac. The contents are dissected off the hernia sac after the sac is opened at the fundus. Omental adhesions if any are released. The intestines are returned to the general peritoneal cavity. Any incarcerated omentum is excised. The ligation of the sac at the neck of the sac is then carried out. The defect of the hernia is then assessed. A defect less than $2 \mathrm{~cm}^{5}$ was considered for anatomical repair in 2 layers ${ }^{5}$ and when the defect was more than $2 \mathrm{~cm}^{6}$ or a less than $2 \mathrm{~cm}$ defect with weak linea alba or rectus sheath, the choice of surgery was a prosthetic mesh repair. A pre-peritoneal plane was created. The prosthetic mesh $^{7}$ (polypropylene) of suitable size to gain more than 2 $\mathrm{cm}$ overlap beyond the defect was placed. The mesh was sutured through a transfascial 8 2-0 polypropylene suture all around (12'o clock, 2'o clock, 4'o clock, 6'o clock, 8'o clock and $10^{\prime}$ o clock). The edges of the defect (neck of the sac) was further approximated in a vertical line commencing at 12'o clock to reach 6 'o clock using 1-0 polypropylene continuous sutures. By this process, the mesh gets totally buried from the skin and subcutaneous tissue. Haemostasis is confirmed. The remnant umbilical flaps are assessed for vascularity and the thinned out avascular portions of the umbilical flaps are excised and refashioning of the umbilicus is done. The flaps are further approximated in a radial fashion from periphery to centre using 3-0 polyglactin sutures (modified star flap ${ }^{9}$ concept). The apices of the umbilical flaps are approximated using one or two layers of circumferential suture of 2-0 polyglactin and this is anchored down to the repaired linea alba to achieve the satisfactory cosmetically sound umbilical pit. At least in few cases, minimal defatening of the subcutaneous plane in the periumbilical area was necessary for a cosmetic outcome. Subcuticular sutures using 4-0 poliglecaprone was used for water tight closure of the umbilical flap within the umbilical pit. Drain was not a necessity in most of the cases. When required, a number 12 suction drain was used. A non-adherent tulle was used to pack the umbilicus and this was subsequently reinforced with gauze pieces soaked in normal saline. A compressing adhesive tape was used (Dynaplast) and the area was left undisturbed till post-operative day 3 . On day 3 the wound was inspected; the vascularity of the flaps was confirmed once again, and a fresh dressing was provided. When drain was used, it was removed on first dressing. Intravenous antibiotics namely Cefuroxime 1.5 grams was used for perioperative cover. Other supportive medications were provided as and when necessary.

Oral diet was initiated on POD 1 except when ileus was a problem. All patients were discharged on POD 3 after the first dressing when they moved their bowels. Second dressing was done on POD 6 in OPD on follow-up. No further dressings were provided and patient was instructed to use Mupirocin ointment (2\%).

Patient was followed up at 2 weeks, 4 weeks, $3^{\text {rd }}$ month, $6^{\text {th }}$ month, $12^{\text {th }}$ month and $18^{\text {th }}$ month. Satisfactory cosmetic outcome was assessed using Visual analogue scale ${ }^{10}$ (given as Table 4). The other parameters looked into on follow-up were surgical site infection, flap necrosis, seroma, recurrence and prolonged pain. Evaluation of functional and cosmetic outcome of transumbilical repair of paraumbilical and umbilical hernias was thus done.

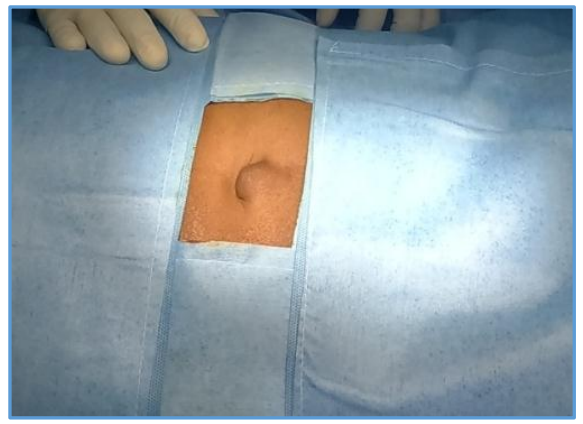

Figure 1. Hernia

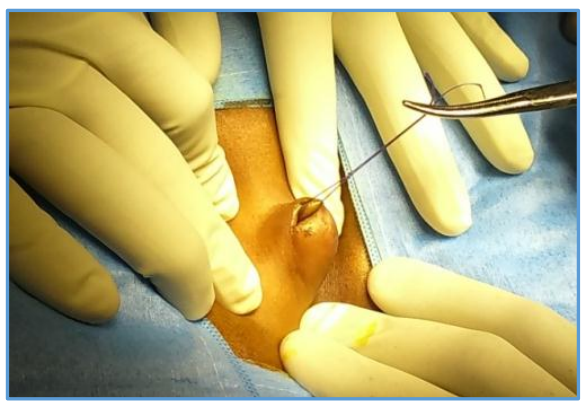

Figure 2. Everting Stitch

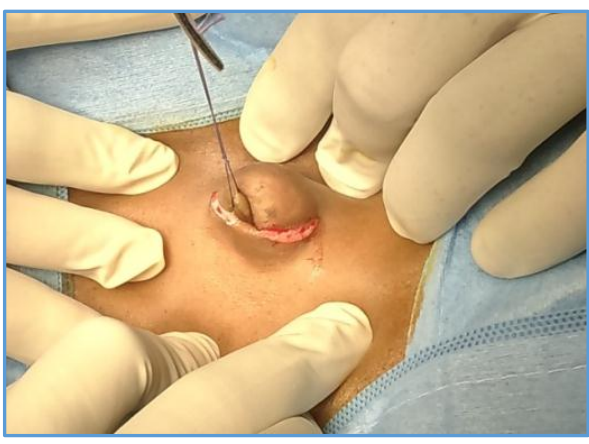

Figure 3. Incision 


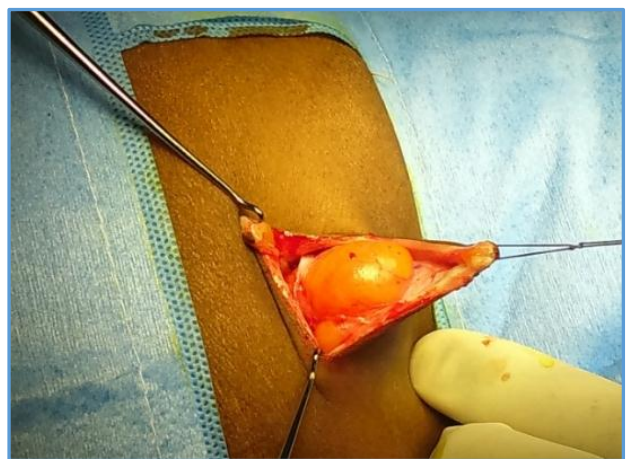

Figure 4. Dissection to the Hernial Sac

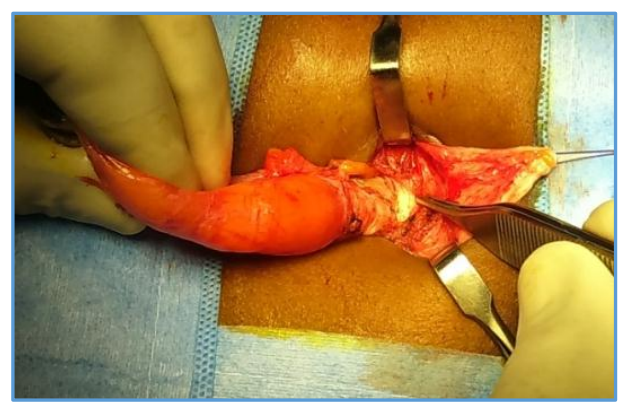

Figure 5. Neck of Sac Defined

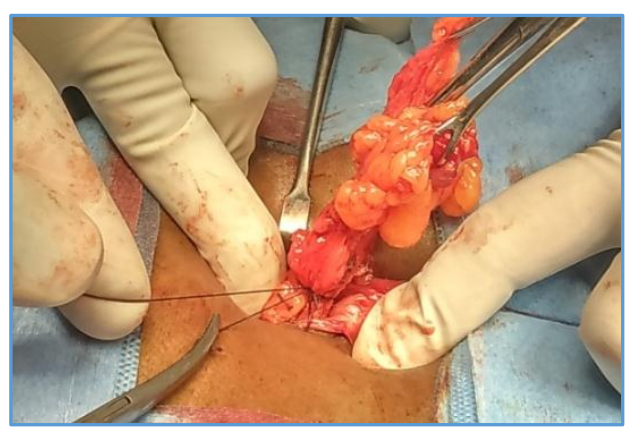

Figure 6. Ligation of the Sac

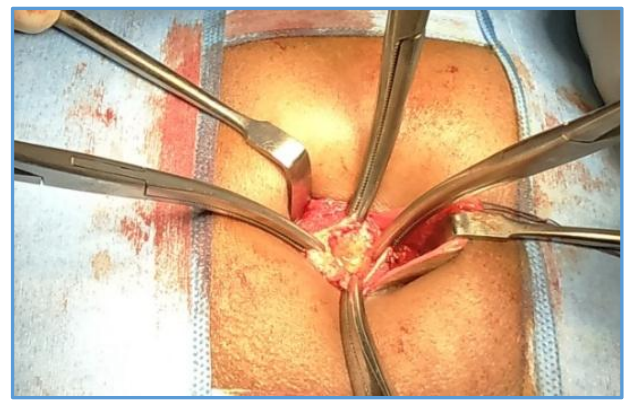

Figure 7. Hernial defect Defined

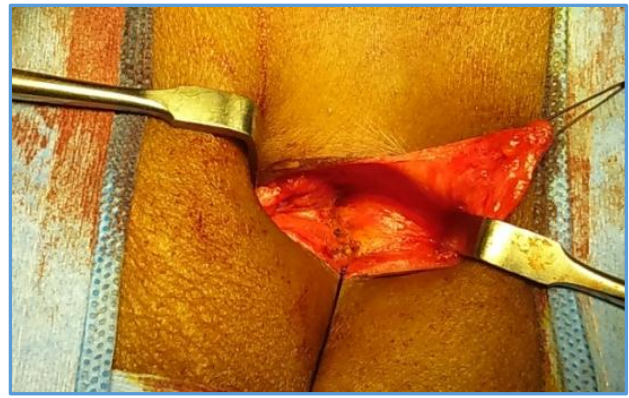

Figure 8. Completed first Layer-12'o Clock to 6'o Clock

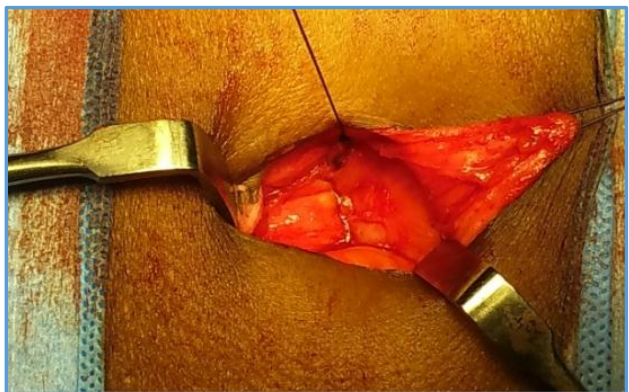

Figure 9. Completed Second Layer- 6 to 12'o Clock

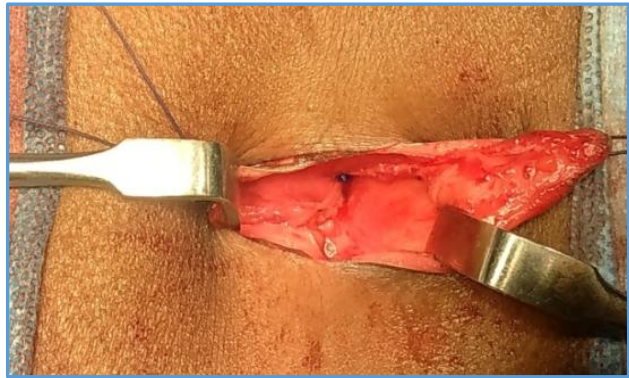

Figure 10. Completed Repair of the Defect

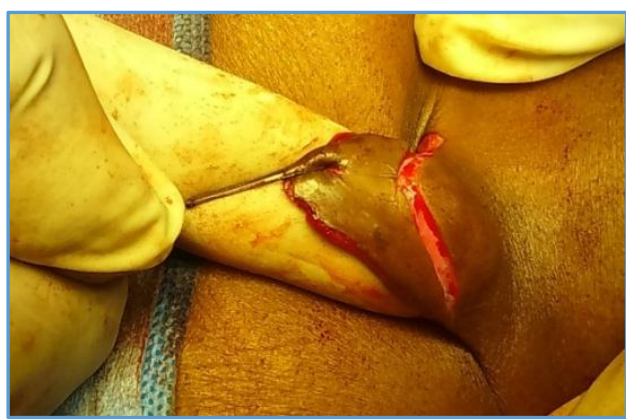

Figure 11. Trimming Off Redundant Skin

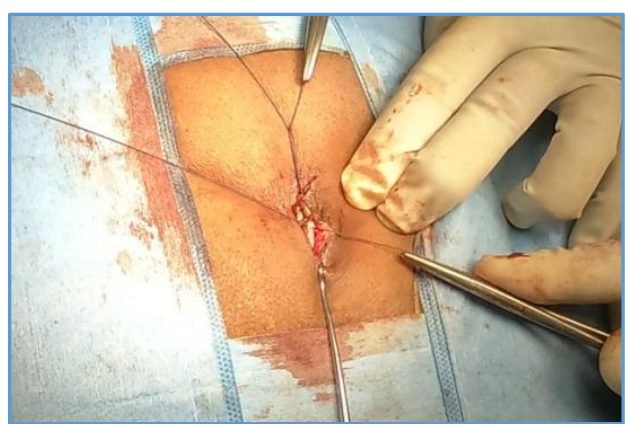

Figure 12. Suturing of Skin Flaps

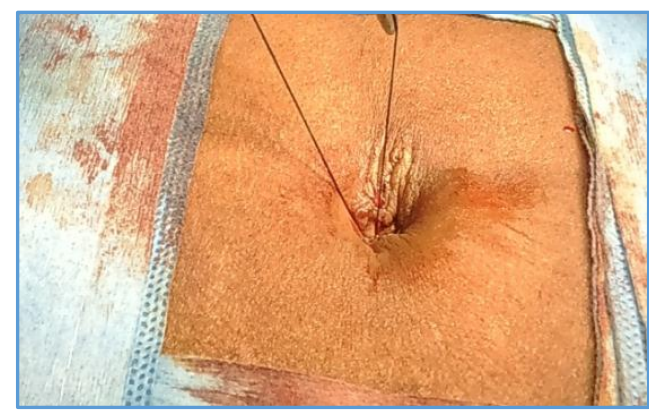

Figure 13. Inverting the Umbilicus back to Linea Alba 


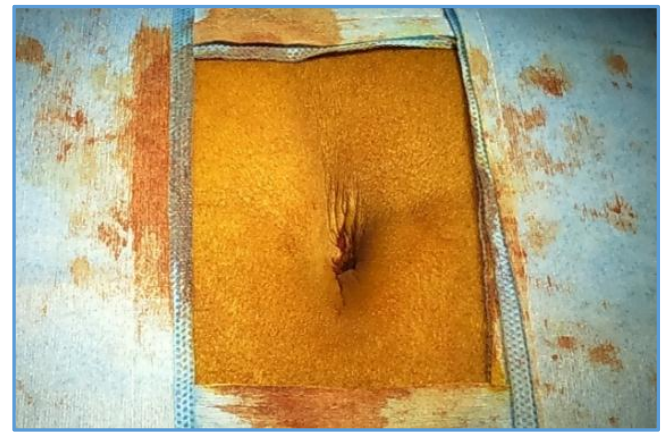

Figure 14. Completed Procedure-Frontal View

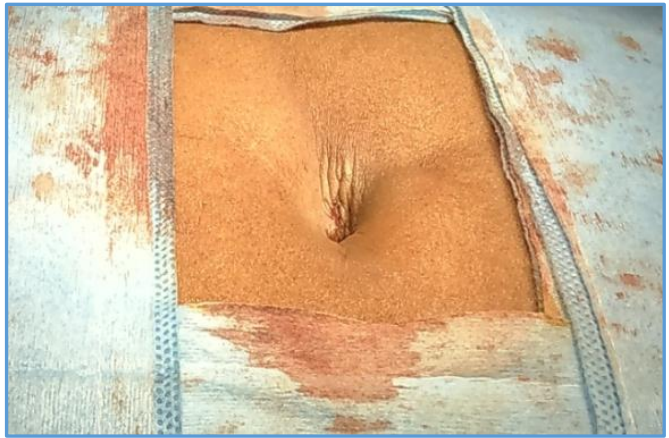

Figure 15. Completed Procedure-Lateral View

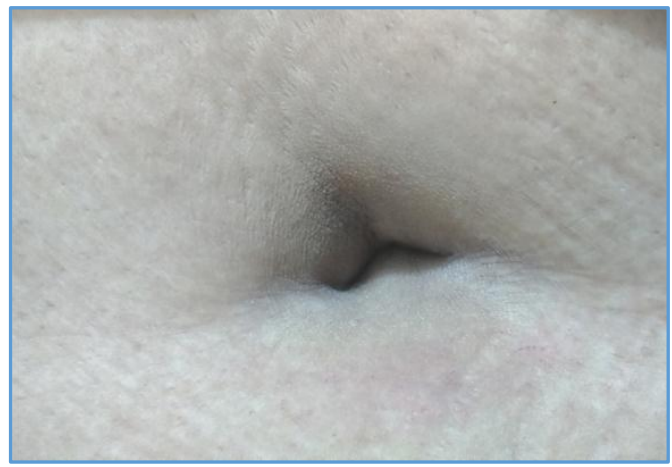

Figure 16. Result at 18 Months

\section{Ethics}

All protocols and procedures followed in this study were in accordance with the ethical standards. Consent from the ethical committee was sought prior to the commencement of the study.

\section{RESULTS}

- Of the 64 patients who underwent the transumbilical repair of PUH, 12 were males and 52 were females.

- Satisfactory primary anatomical repair was possible in 48 patients of the 64 .

- Prosthetic polypropylene mesh was a requirement in 16 of 64 patients.

- SSI was nil.

- Flap necrosis marginal towards the apex of the umbilical flaps were seen in 3 out of 64 patients.

- Seroma/ persistent discharge occurred in 1 patient which resolved in 2 months' time with no long-term sequelae.

- Recurrence occurred in 1 patient, in whom primary anatomical repair was carried out.
- Pain as a post-operative debilitating symptom was seen in none.

- The cosmetic outcome was assessed using visual analogue scale.

- Patient gave a score of 2 in 2 cases, 1 in 53 cases and 0 in 9 cases.

- Score given by the blinded peer was 1 in 38 cases and 0 in 26 cases.

\begin{tabular}{|c|c|}
\hline Male & 12 \\
\hline Female & 52 \\
\hline Total & $\mathbf{6 4}$ \\
\hline \multicolumn{2}{|c|}{ Table 1. Sex Distribution } \\
\hline
\end{tabular}

\begin{tabular}{|c|c|}
\hline Type of Repair & Number of Cases \\
\hline Primary anatomical repair & 48 \\
\hline Prosthetic mesh repair & 16 \\
\hline \multicolumn{2}{|c|}{ Table 2. Type of Repair } \\
\hline
\end{tabular}

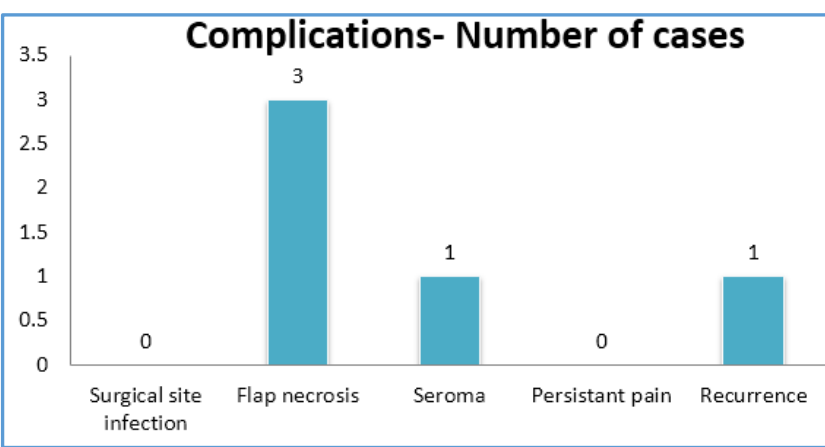

Chart 1. Complications

\begin{tabular}{|c|c|}
\hline Degree & Appearance \\
\hline 0 & Normal appearance \\
\hline 1 & $\begin{array}{c}\text { Minimal disparity barely noticeable from a short } \\
\text { distance }\end{array}$ \\
\hline 2 & $\begin{array}{c}\text { Mild disparity noticeable, but with no } \\
\text { disfigurement }\end{array}$ \\
\hline 3 & $\begin{array}{c}\text { Moderate disparity noticeable with mild } \\
\text { disfigurement }\end{array}$ \\
\hline 4 & Severe disparity with moderate disfigurement \\
\hline 5 & Table 3. Visual Analogue Scale \\
\hline
\end{tabular}

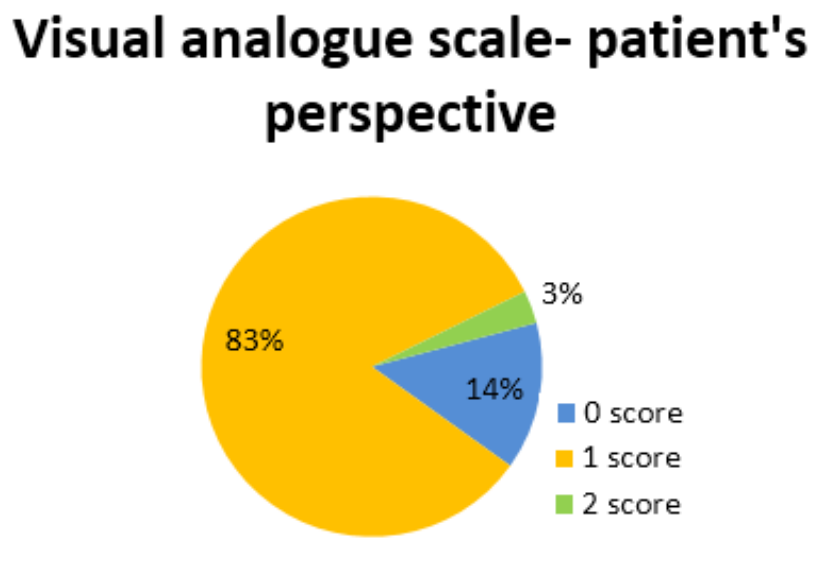

Chart 2. Visual Analogue Scale Results- Patient's Perspective 


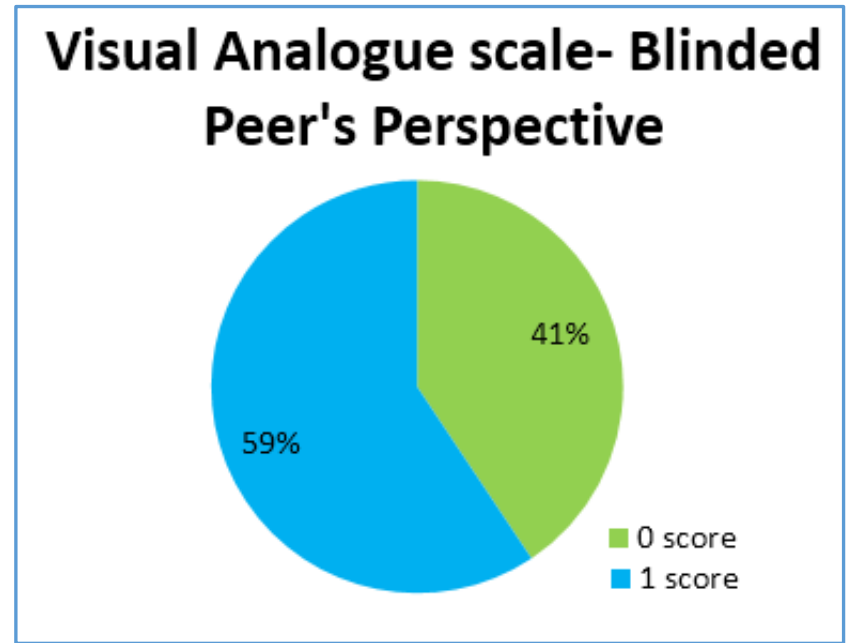

Chart 3. Visual Analogue Scale Results-Blinded Peer's Perspective

\section{DISCUSSION}

From the statement of Sir. John Bruce-11,12

"The final word on hernia will probably never be written. In collecting, assimilating and distilling the wisdom of today we must provide a base from which further advance may be made."

It is clear that there is no definite tailored technique for any hernia. The ultimate aim of a surgeon would therefore be to provide a recurrence free, 13 pain free, cosmetically sound result for patient to get along with his day-to-day life activities uninterrupted. Compared to the time tested 14 Mayo's repair or presently in vogue laparoscopic repair, the transumbilical repair stand in a different platform. This repair gives opportunity to the surgeon a satisfactory cosmetic recontouring of the umbilicus in addition to all what is possible by either Mayo or laparoscopic repair.15 The results achieved in this study are testifying facts, which support the claim that the transumbilical repair will get accepted as another standard procedure for the definitive management of umbilical and paraumbilical hernias.

\section{CONCLUSION}

The transumbilical repair in addition to the standard repair of defect gives a vivid opportunity to the surgeon to cosmetically reconstruct the umbilicus leaving no noticeable scar. This procedure is therefore a superior method of repair in comparison to the conventional open surgery or even the currently in vogue laparoscopic surgery.

\section{REFERENCES}

[1] Rodriguez JA, Hinder RA. Surgical management of umbilical hernia. Operat Techniq General Surg 2004;6(3):156-64.
[2] Stirler VM, Schoenmaeckers EJ, de Haas RJ, et al. Laparoscopic repair of primary and incisional ventral hernias: the difference must be acknowledged: a prospective cohort analysis of 1,088 consecutive patients. Surg Endosc 2014;28(3):891-5.

[3] Colon MJ, Kitamura R, Telem DA, et al. Laparoscopic umbilical hernia repair is the preferred approach in obese patients. Am J Surg 2013;205(2):231-6.

[4] Sodergren MH, Swift I. Seroma formation and method of mesh fixation in laparoscopic ventral hernia repairhighlights of a case series. Scand J Surg 2010;99(1):247.

[5] Kumar MD. Long-term outcomes in laparoscopic vs. open ventral hernia repair. World J Laparosc Surg 2008;1(2):32-5.

[6] Tsimoyiannis EC, Tsimogianni KE, Pappas-Gogos G, et al. Seroma and recurrence in laparoscopic ventral hernioplasty. JSLS 2008;12(1):51-7.

[7] Misra MC, Bansal VK, Kulkarni MP, et al. Comparison of laparoscopic and open repair of incisional and primary ventral hernia: results of a prospective randomized study. Surg Endosc 2006;20(12):1839-45.

[8] Chowbey PK, Sharma A, Mehrotra M, et al. Laparoscopic repair of ventral/incisional hernias. J Minim Access Surg 2006;2(3):192-8.

[9] Ramshaw BJ, Esartia P, Schwab J, et al. Comparison of laparoscopic and open ventral herniorrhaphy. Am Surg 1999;65(9):827-31.

[10] Castro PM, Rabelato JT, Monteiro GG, et al. Laparoscopy versus laparotomy in the repair of ventral hernias: systematic review and meta-analysis. Arq Gastroenterol 2014;51(3):205-11.

[11] Carbajo MA, de Olmo JC, Blanco JI, et al. Laparoscopic treatment of ventral abdominal wall hernias: preliminary results in 100 patients. JSLS 2000;4(2):141-5.

[12] Stranding S. Gray's anatomy. The anatomical basis of clinical practice. $41^{\text {st }}$ edn. Elsevier, 2015.

[13] Farquharson M, Moran B, Farquharson EL. Farquharson's text book of operative general surgery. 9th edn. London: Hodder Arnold Taylor and Francis Group 2005.

[14] Nguyen SQ, Divino CM, Buch KE, et al. Postoperative pain after laparoscopic ventral hernia repair: a prospective comparison of sutures versus tacks. JSLS 2008;12(2):113-6.

[15] Bedi AP, Bhatti T, Amin A, et al. Laparoscopic incisional and ventral hernia repair. J Minim Access Surg 2007;3(3):83-90. 